\title{
Tsunami hazard warning and risk prediction based on inaccurate earthquake source parameters
}

\author{
Katsuichiro Goda ${ }^{1}$ and Kamilla Abilova ${ }^{2}$ \\ ${ }^{1}$ Department of Civil Engineering, Queen's School of Engineering, University of Bristol, Queen's Building, University Walk, \\ Bristol, BS8 1TR, UK \\ ${ }^{2}$ Department of Engineering Science, University of Oxford, Parks Road, Oxford, OX1 3PJ, UK \\ Correspondence to: Katsuichiro Goda (katsu.goda@bristol.ac.uk)
}

Received: 1 December 2015 - Published in Nat. Hazards Earth Syst. Sci. Discuss.: 18 December 2015

Revised: 15 February 2016 - Accepted: 16 February 2016 - Published: 29 February 2016

\begin{abstract}
This study investigates the issues related to underestimation of the earthquake source parameters in the context of tsunami early warning and tsunami risk assessment. The magnitude of a very large event may be underestimated significantly during the early stage of the disaster, resulting in the issuance of incorrect tsunami warnings. Tsunamigenic events in the Tohoku region of Japan, where the 2011 tsunami occurred, are focused on as a case study to illustrate the significance of the problems. The effects of biases in the estimated earthquake magnitude on tsunami loss are investigated using a rigorous probabilistic tsunami loss calculation tool that can be applied to a range of earthquake magnitudes by accounting for uncertainties of earthquake source parameters (e.g., geometry, mean slip, and spatial slip distribution). The quantitative tsunami loss results provide valuable insights regarding the importance of deriving accurate seismic information as well as the potential biases of the anticipated tsunami consequences. Finally, the usefulness of rigorous tsunami risk assessment is discussed in defining critical hazard scenarios based on the potential consequences due to tsunami disasters.
\end{abstract}

\section{Introduction}

Tsunami hazard maps and early warning systems are essential for mitigating the consequences of catastrophic tsunami disasters. Prior to actual detection of tsunamis, warnings can be issued based on earthquake information (e.g., magnitude and hypocenter location). Tsunami warning systems detect off-shore tsunami waves and issue updated warnings to resi- dents in coastal communities based on the observations and modified earthquake information. In coastal areas, people evacuate to designated high grounds and shelters following local hazard maps and real-time instructions by emergency officers. The importance of these tsunami risk management tools (together with hard engineering mitigation measures) can be understood by comparing two massive events, the 2004 Indian Ocean tsunami and the 2011 Tohoku tsunami. The tsunami early warning systems were not deployed prior to the 2004 tsunami and there was no tsunami protection along the coast, resulting in 230000+ fatalities (Murata et al., 2010). On the other hand, the early warning systems were in place and operational during the 2011 Tohoku tsunami, saving many lives (Fraser et al., 2013).

Issuing accurate and prompt tsunami warnings to residents in coastal areas is critically important for mega-thrust tsunamigenic earthquakes. During the initial phase, it requires reliable estimation of key earthquake source characteristics, such as magnitude and location. The estimation of earthquake information is usually accurate and prompt however, for very large earthquakes satisfactory performance may not be achieved during the early phase of evacuation. This can be exemplified for the 2011 Tohoku tsunami case (Hoshiba and Ozaki, 2014). The first estimate of the Japan Meteorological Agency (JMA) magnitude was Mj7.9 (3 min after the earthquake) and later was updated to $\mathrm{Mj} 8.4$ (74 min after the earthquake). The significant underestimation was caused by the saturation of $\mathrm{Mj}$. A correct estimate of the moment magnitude $\left(M_{\mathrm{w}}\right)$ equal to 8.8 (and eventually to 9.0 ) was reached $134 \mathrm{~min}$ after the earthquake. It took a considerably long time to reach the correct $M_{\mathrm{w}}$ value because 
seismograms recorded at broadband stations in Japan had exceeded the maximum amplitudes of the instruments. On the other hand, overseas agencies, such as the US Geological Survey, obtained correct estimates of $M_{\mathrm{w}}$ about $20 \mathrm{~min}$ after the earthquake using teleseismic signals recorded outside of Japan. Consequently, tsunami warnings issued by the JMA underestimated the observed tsunamis significantly (3 to $6 \mathrm{~m}$ versus $10+\mathrm{m}$; Cyranoski, 2011). Different estimates of the earthquake source parameters have significant influence on the wave heights and inundation depths because seismic events of $M_{\mathrm{w}} 8.0$ and $M_{\mathrm{w}} 9.0$, for instance, correspond to very different tsunami hazard scenarios in terms of size and earthquake slip. It is important to point out that recent new developments for rapid and reliable estimation of earthquake magnitude will definitely contribute to the reduction of uncertainties associated with estimated magnitudes in the early phase of tsunami disasters (Kanamori and Rivera, 2008; Melgar et al., 2015).

From viewpoints of tsunami early warning and tsunami risk management, uncertainty of hazard and risk predictions based on macroscopic earthquake parameters (i.e., magnitude and hypocenter) have important implications. For a $M_{\mathrm{w}} 9$.0-class mega-thrust subduction event, the fault plane of the earthquake rupture extends to distances over several hundred kilometers (Murotani et al., 2013). Moreover, spatial distribution of earthquake slip varies significantly and these rupture characteristics, which are not captured by the earthquake magnitude and location, have major influence on tsunami waves and inundation in coastal cities and towns (Goda et al., 2014, 2015; Fukutani et al., 2015; Mueller et al., 2015). This often leads to significant uncertainty in predicted consequences due to tsunamis (Goda and Song, 2016). In addition, with increasing earthquake magnitude, both amplitude and spatial extent of tsunamis increase rapidly. Hence, warnings should be issued in recognition of accuracy of the earthquake parameters and inherent uncertainty of the tsunami risk predictions. Nonetheless, this is not straightforward because the tsunami damage and loss generation processes are highly nonlinear and variable.

This study investigates the effects due to underestimation of the earthquake source parameters in the context of tsunami early warning and tsunami risk assessment. The 2011 Tohoku earthquake is focused on as a case study to illustrate the significance of the problems from a retrospective perspective. In the case study, a building portfolio consisting of about 86000 buildings in Miyagi Prefecture is considered. The problem is set up as follows. A tsunami event of $M_{\mathrm{w}} 9.0$ in the offshore areas of the Tohoku region is adopted as reference. The magnitude of this event may be underestimated significantly during the early stage of the disaster (as was the case for the 2011 tsunami). The underestimated scenarios are represented by a set of earthquake scenarios with lower moment magnitudes than the reference scenario. For each assumed scenario, stochastic source models are generated by taking into account the uncertainty of tsunami source characteristics. Us- ing the multiple sets of tsunami source models corresponding to different moment magnitudes, probabilistic tsunami loss estimation is carried out. By analyzing the estimated tsunami loss for coastal cities and towns in Miyagi Prefecture, potential biases due to underestimation of earthquake magnitude can be quantified. These results provide useful insights regarding the importance of deriving accurate seismic information and can be compared with the effects due to uncertain source characteristics (e.g., geometry and spatial slip distribution) for given moment magnitudes, which is unavoidable in making risk predictions based on macroscopic earthquake parameters only.

For this purpose, a new probabilistic tsunami loss model for large $M_{\mathrm{w}} 8.0+$ earthquakes in the Tohoku region of Japan is developed. For a given scenario magnitude, the loss model generates a tsunami loss curve for a building portfolio by considering uncertainties in earthquake source parameters (e.g., geometry, mean slip, and spatial slip distribution). In particular, a stochastic source modeling method (Mai and Beroza, 2002; Goda et al., 2014) is incorporated, and nonlinear shallow water equations with run-up are evaluated for each source model, enabling accurate inundation simulation. To extend the analyses to different earthquake scenarios, scaling relationships for the source parameters (Mai and Beroza, 2002; Murotani et al., 2013; Thingbaijam and Mai, 2016) are employed to generate stochastic source models that correspond to different moment magnitudes. Subsequently, Monte Carlo tsunami simulation is carried out, and inundation results at building locations are integrated with tsunami fragility curves and damage cost models that are applicable to the buildings of interest (Goda and Song, 2016). The novelty of the current tsunami loss model, with respect to other developments (e.g., Wiebe and Cox, 2014; Goda and Song, 2016), is that generation of uncertain tsunami scenarios is not specific for (inverted) source models and can be applied to a range of scenarios in terms of earthquake magnitude. This is one step closer to the so-called probabilistic tsunami hazard analysis (PTHA; Geist and Parsons, 2006; Horspool et al., 2014), where multiple rupture scenarios are accounted for together with their occurrence probabilities. It is noteworthy that assignment of occurrence probability to extremely large earthquakes involves large uncertainty and may be unreliable (Kagan and Jackson, 2013). For this reason, occurrence probabilities for the large earthquakes are not considered in this study. It is noted that typical PTHA studies do not perform full inundation simulations and tsunami hazard parameters estimated at off-shore locations are extrapolated into land areas. Therefore, the extension of the current PTHA methodology to tsunami risk and loss estimation is limited by the fact that the accurate inundation simulation at local city/town levels is not performed and it is not possible to evaluate the tsunami damage and loss to individual buildings. The developed tsunami loss model in this study overcomes these limitations. 


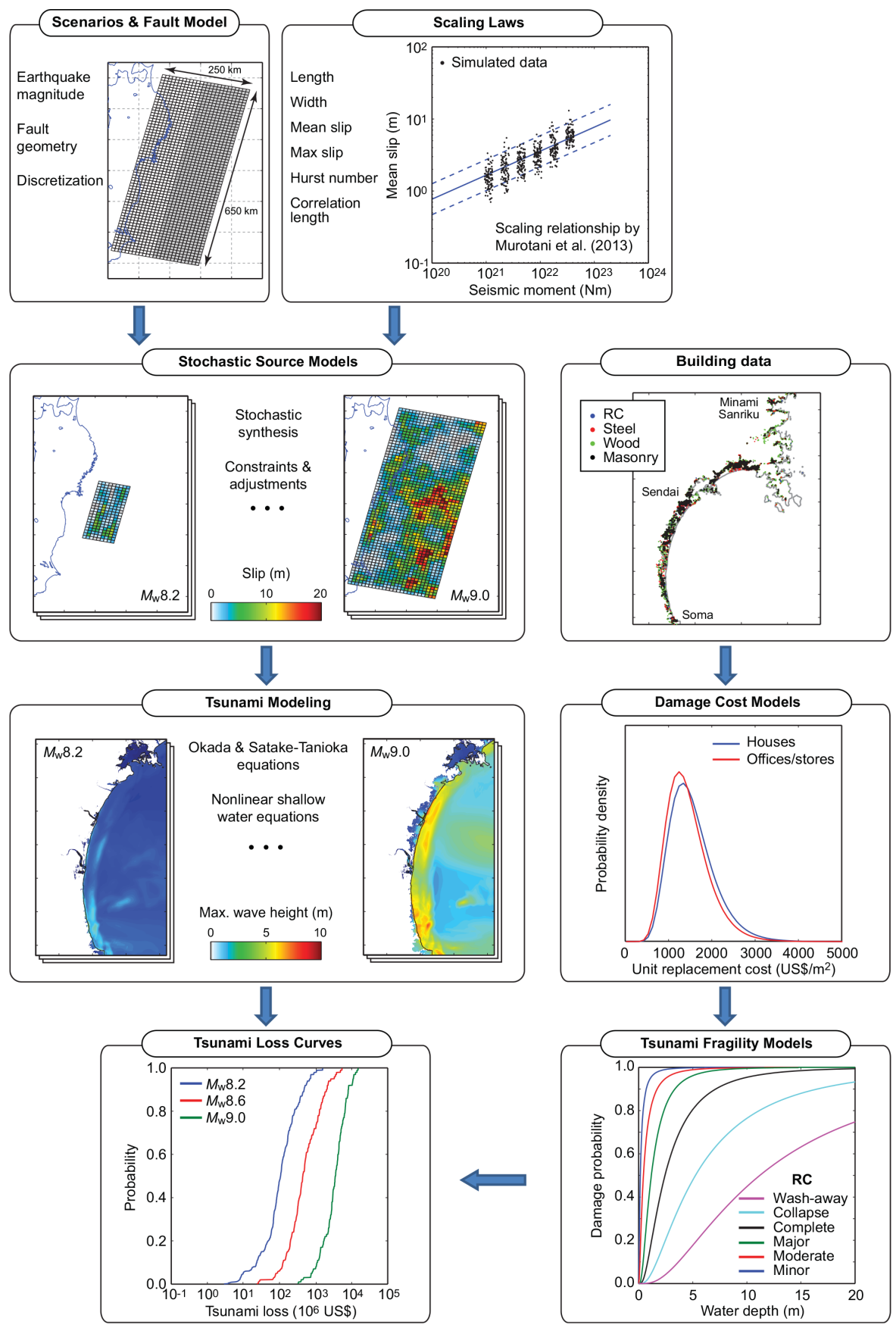

Figure 1. Probabilistic tsunami hazard and risk analysis.

The paper is organized as follows. First, the methodology for probabilistic tsunami loss estimation is explained. Subsequently, a numerical example is set up for large subduction earthquakes $\left(M_{\mathrm{w}} 8.0\right.$ to $\left.M_{\mathrm{w}} 9.0\right)$ off the Tohoku coast. The results of the tsunami loss estimation for the building portfolio in Miyagi Prefecture are obtained and are compared for different cases. In particular, the effects of different scenario magnitudes and uncertain source characteristics on tsunami loss are investigated from the viewpoints of tsunami early warning. Finally, conclusions are drawn for the use of advanced tsunami loss estimation tools in tsunami risk management. 


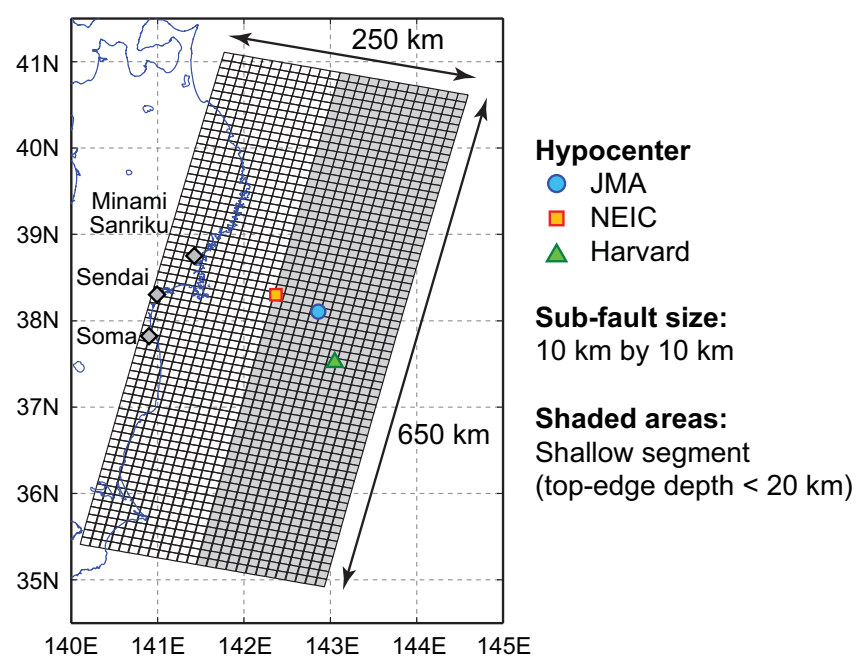

Figure 2. Tsunami source region off the Tohoku coast of Japan.

\section{Probabilistic tsunami loss estimation for multiple scenario magnitudes}

This section presents a computational framework for probabilistic tsunami loss estimation that is applicable to a range of scenario magnitudes. The method is the generalized version of the stochastic tsunami loss model (Goda and Song, 2016). It consists of five components: (i) earthquake scenario generation, (ii) stochastic source modeling, (iii) tsunami inundation modeling, (iv) building exposure data, and (v) tsunami damage assessment and loss estimation. A computational flow of the tsunami loss model is illustrated in Fig. 1. Succinct descriptions of the model components are given below. The descriptions are based on the Tohoku region of Japan.

\subsection{Earthquake scenario and scaling laws for source parameters}

A seismic source region for possible large earthquakes is defined. The source region needs to be sufficiently large such that a $M_{\mathrm{w}} 9.0$-class event, which is regarded as an upper limit in this study, can be accommodated. For the Tohoku region, a fault plane with $650 \mathrm{~km}$ in length and $250 \mathrm{~km}$ in width is considered (Fig. 2). The fault plane has a constant strike of 193 degrees and variable dip angles, gradually steepening from 8 to $16^{\circ}$ along the down-dip direction. The geometry and location of the fault plane are determined based on the source model for the 2011 Tohoku earthquake, developed by Satake et al. (2013), and are consistent with other source models for the Tohoku event (Goda et al., 2014). The fault plane is discretized with sub-faults having a size of $10 \mathrm{~km}$ by $10 \mathrm{~km}$. Later, sub-faults of non-zero slips are determined based on sampled fault length and width of a seismic event for an assumed value of $M_{\mathrm{w}}$, and slip values of these sub-faults are synthesized using stochastic synthesis methods (Sect. 2.2).
The shaded areas in Fig. 2 are sub-faults having the topedge depth shallower than $20 \mathrm{~km}$. The source inversion models considered by Goda et al. (2014) indicate that large slips tend to occur within the gently-dipping shallow segments along the Japan Trench. This empirical knowledge can be used as a constraint in selecting suitable synthesized slip distributions. Moreover, Fig. 2 shows the estimated hypocenter locations by three institutions, i.e., JMA, US Geological Survey (NEIC), and Harvard Seismology Group. The hypocenter locations are variable and are apart from each other by more than $50 \mathrm{~km}$, showing variability of the hypocenter location for a very large earthquake. In the context of early warning, the observed hypocenter locations can also be used to determine the acceptance of candidate slip models in stochastic source simulation. It is noteworthy that the hypocenter location does not exactly correspond to the so-called asperity areas with the largest slip but is located within areas of moderate slip near the asperities (Mai et al., 2005). Therefore, the hypocenter position, which is uncertain, gives only a loose constraint of areas with large deformation which cause major tsunami waves.

Empirical scaling laws describe relationships between seismological parameters (e.g., fault geometry and slip statistics) and earthquake size parameters, such as $M_{\mathrm{w}}$ and seismic moment $M_{\mathrm{o}}$ (note: $\log _{10} M_{\mathrm{o}}=1.5 M_{\mathrm{w}}+9.1 ; M_{\mathrm{o}}$ in Nm). Many equations are available in the literature for different earthquake types (e.g., Wells and Coppersmith, 1994). To synthesize earthquake source models that have realistic features, a set of scaling laws and empirical models for the key source parameters is implemented. To account for the uncertainty of these parameters, probabilistic information of the adopted scaling laws and empirical models, which is summarized in Table 1, is taken into consideration in the simulation.

More specifically, three types of source parameters are considered in this study. The first type is related to fault geometry: the fault rupture area $S(=L \times W)$ and aspect ratio $L / W$, in which $L$ and $W$ are the fault length and width, respectively. The scaling relationship for $S$, developed by Murotani et al. (2013), is adopted, while the aspect ratio is treated as a uniform random variable between 1.5 and 3.0 (i.e., $L>W$ ), according to typical fault plane configurations of the inverted source models of the 2011 Tohoku earthquake (Goda et al., 2014).

The second type is related to slip statistics: average slip $D_{\text {ave }}$ and maximum slip $D_{\max }$ (across the fault plane). The scaling relationships developed by Murotani et al. (2013) and Thingbaijam and Mai (2016) are considered for $D_{\text {ave }}$ and $D_{\max }$, respectively. Because both $D_{\text {ave }}$ and $D_{\max }$ are treated as random variables, the physical constraint that the maximum slip is sufficiently greater than the average slip is implemented by requiring $D_{\max }>1.5 \times D_{\text {ave }}$. Moreover, in generating source model parameters probabilistically, the consistency among seismic moment, rupture area, and average slip is achieved based $M_{\mathrm{o}}=\mu S D_{\text {ave }}$, in which $\mu$ is the rock rigidity and is taken as $40 \mathrm{GPa}$ in this study. Due to the variability 
Table 1. Summary of empirical scaling laws and probabilistic information of fault geometry and stochastic source parameters adopted in this study. $N(0,1)$ represents the standard normal random variable, whereas $U(a, b)$ represents the uniform random variable with lower and upper limits of $a$ and $b$, respectively.

\begin{tabular}{lll}
\hline Parameter & Equation & Reference \\
\hline Surface area $S\left(\mathrm{~km}^{2}\right)$ & $\log _{10} S=-9.873+(2 / 3) M_{\mathrm{o}}+0.1875 N(0,1)$ & Murotani et al. (2013) \\
Aspect ratio $L / W$ & $L / W=U(1.5,3.0)$ & Goda et al. (2014) \\
Average slip $D_{\text {ave }}(\mathrm{m})$ & $\log _{10} D_{\mathrm{ave}}=-6.780+(1 / 3) M_{\mathrm{O}}+0.2148 N(0,1)$ & Murotani et al. (2013) \\
Maximum slip $D_{\max }(\mathrm{m})$ & $\log _{10} D_{\max }=0.624+0.948 \times \log _{10}\left(D_{\mathrm{ave}}\right)+0.10 N(0,1)$ & Thingbaijam and Mai (2016) \\
Hurst number $H$ & $H=0.75+0.23 N(0,1)$ & Mai and Beroza (2002) \\
Correlation length along dip $A_{z}(\mathrm{~km})$ & $\log _{10} A_{z}=-1.79+0.38 M_{\mathrm{W}}+0.17 N(0,1)$ & Mai and Beroza (2002) \\
Correlation length along strike $A_{x}(\mathrm{~km})$ & $\log _{10} A_{x}=-2.43+0.49 M_{\mathrm{W}}+0.15 N(0,1)$ & Mai and Beroza (2002) \\
Box-Cox parameter $\lambda$ & $\lambda=U(0.1,0.3)$ & Goda et al. (2014) \\
\hline
\end{tabular}

in $S$ and $D_{\text {ave }}$, (independent) random sampling of $S$ and $D_{\text {ave }}$ may result in a seismic moment that is very different from the target seismic moment or moment magnitude. To avoid such an inadequate combination of $S$ and $D_{\text {ave }}$, sampling of these two parameters is repeated until the calculated seismic moment falls within a certain range; in this study, the target moment magnitudes minus/plus 0.05 units are considered for such a range. For instance, when the target moment magnitude is set to 9.0, sampling of $S$ and $D_{\text {ave }}$ is continued until the calculated moment magnitude falls between 8.95 and 9.05 .

The third type is related to the spatial slip distribution and characterizes the heterogeneity of earthquake slip across the fault plane. In this study, four parameters are considered: Hurst number $H$, correlation lengths in down-dip and along-strike directions $A_{z}$ and $A_{x}$, and Box-Cox parameter $\lambda$. The Hurst number and correlation lengths define the spectral characteristics of the slip distribution in wavenumber (see Eq. (1) in Sect. 2.2). The Hurst number is modeled as a uniform random variable with respect to moment magnitude, whereas the correlation lengths increase with moment magnitude (Mai and Beroza, 2002). The Box-Cox parameter is used to generate slip distributions with heavy right tails, which is a notable common feature from the inversion models of the 2011 Tohoku earthquake (Goda et al., 2014). Additional explanations of these parameters are given in Sect. 2.2 where stochastic synthesis of constrained slip distribution is mentioned.

To illustrate the generation of the above-mentioned source parameters, simulated samples of the fault area, average slip, maximum slip, and correlation lengths in down-dip and along-strike directions are shown in Fig. 3 for a range of moment magnitudes $\left(M_{\mathrm{w}} 8.0\right.$ to $\left.M_{\mathrm{w}} 9.0\right)$. The sample size per moment magnitude is 100. In Fig. 3, the adopted scaling relationships as well as the source parameters for the 11 inversion models of the 2011 Tohoku earthquake, obtained by Goda et al. (2014), are also included. The comparisons of the generated source parameters with the scaling laws indicate that all source parameters, except for the maximum slip, follow closely the scaling relationships and are consistent with the parameters obtained for the 2011 Tohoku earthquake. The simulated maximum slip is generally greater than the empirical relationship by Thingbaijam and Mai (2016), noting that the maximum slip values from the 11 source models for the 2011 Tohoku earthquake (Goda et al., 2014) are significantly larger than the Thingbaijam-Mai relationship. Note that the results shown in Fig. $3 c$ are the final accepted values, which are modified from originally sampled values of the maximum slip (see the explanations of constraints discussed in Sect. 2.3). In light of the large differences of the maximum slip between the Thingbaijam-Mai model and the results for the 2011 Tohoku earthquake, the simulated maximum slip values are considered to be acceptable.

\subsection{Stochastic source models}

The spectral synthesis of random fields generates earthquake slip distributions that have desirable spatial characteristics, expressed in terms of wavenumber spectra in down-dip and along-strike directions (Mai and Beroza 2002). A brief summary of the stochastic method is given below; full details of the method can be found in Goda et al. (2014) and are not repeated here.

The wavenumber power spectrum can be modeled based on a von Kármán auto-correlation function:

$$
P(k) \propto \frac{A_{x} A_{z}}{\left(1+k^{2}\right)^{H+1}},
$$

where $k$ is the wavenumber, $k=\left(A_{z}^{2} k_{z}^{2}+A_{x}^{2} k_{x}^{2}\right)^{0.5}$. In the von Kármán model, $A_{z}$ and $A_{x}$ control the absolute level of the power spectrum in the low wavenumber range (i.e., $k \ll 1$; long wavelength) and capture the anisotropic spectral features of the slip distribution (when $A_{z} \neq A_{x}$ ). $H$ determines the slope of the power spectral decay in the high wavenumber range (i.e., short wavelength), and is theoretically constrained to fall between 0 and 1 . As mentioned in the previous section, the scaling relationships for $H, A_{x}$, and $A_{z}$ are available (Table 1), and can be used in stochastic source simulation. Realizations of slip distributions with desirable spectral features are generated using a Fourier integral method 

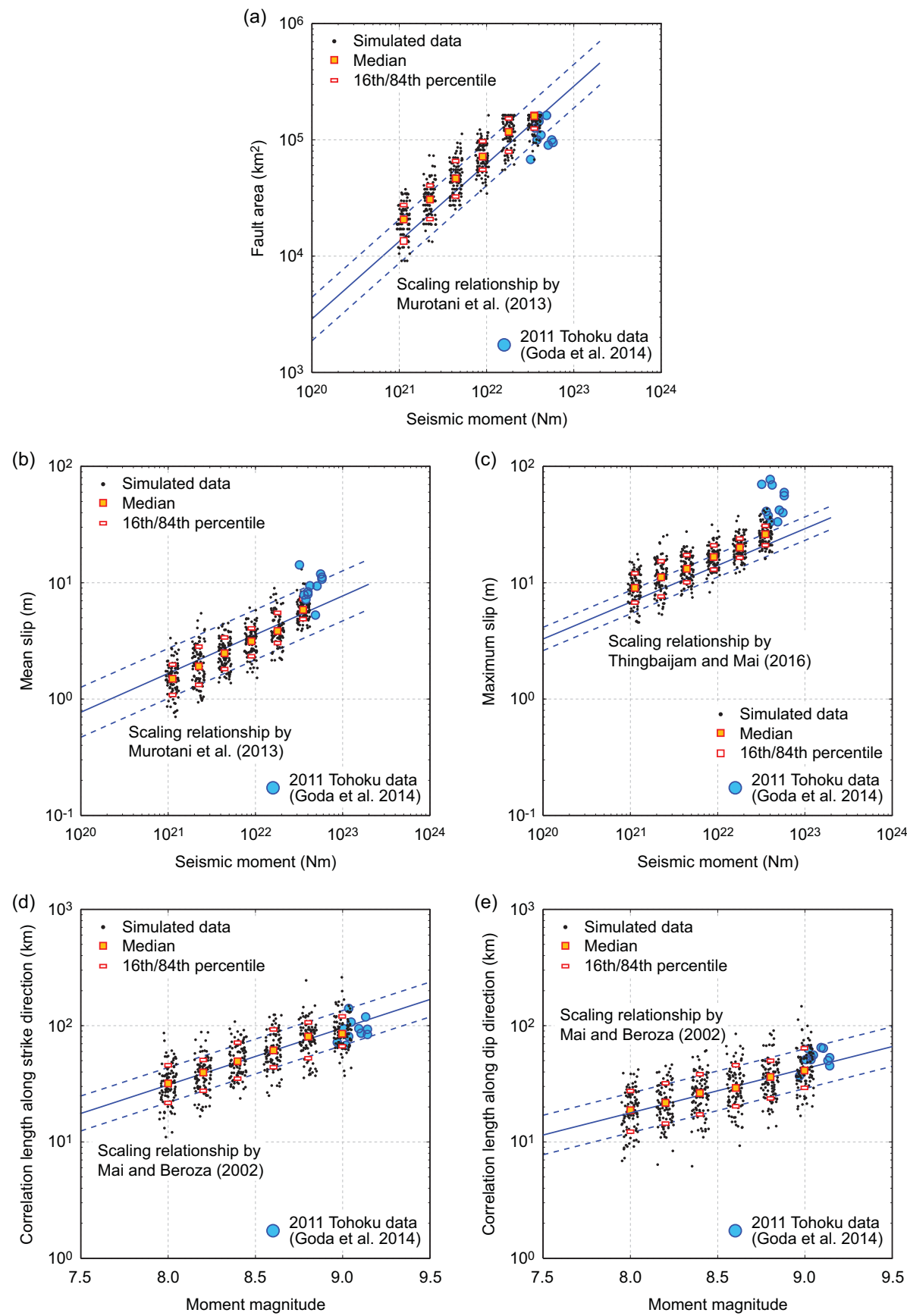

Figure 3. Scaling relationships and simulated parameters in stochastic scenario generation: (a) seismic moment - fault area, (b) seismic moment - mean slip, (c) seismic moment - maximum slip, (d) moment magnitude - correlation length along strike direction, and (e) moment magnitude - correlation length along dip direction.

(Pardo-Iguzquiza and Chica-Olmo, 1993). For a given set of $H, A_{x}$, and $A_{z}$, the amplitude spectrum of the target slip distribution is defined as in Eq. (1), while the phase spectrum is represented by a random phase matrix. The constructed complex Fourier coefficients are transformed into the spatial domain via two-dimensional inverse fast Fourier transform. The generated slip distributions have slip values that are nor- mally distributed (i.e., symmetrical with respect to mean). To achieve realistic heavy right-tail features of the slip distribution (i.e., positive skewness), the synthesized slip distribution is converted via Box-Cox transformation: $y=\left(x^{\lambda}-1\right) / \lambda$ $(\lambda \neq 0)$, in which $y$ is the transformed slip and $x$ is the original slip (note: when $\lambda=0, y=\log (x)$ ). Subsequently, the transformed slip distribution is adjusted to achieve the target 
mean slip $D_{\text {ave }}$ (which is also simulated in stochastic source modeling) and to avoid very large slip values exceeding the target maximum slip $D_{\max }$. The excessive slip values are resampled from a histogram that is constructed based on slip values between $0.67 D_{\max }$ and $D_{\max }$ (Mai et al., 2005).

Subsequently, the position of the fault plane is determined randomly within the whole source region (Fig. 2) but ensuring that the fault plane contains the hypocenter location (to be consistent with the situation for tsunami early warning). It is noteworthy that the hypocenter location is uncertain and can vary significantly (Fig. 2). To account for this uncertainty, for each synthetic source model, a location of the hypocenter is sampled from four locations; three are based on the JMA, USGS, and Harvard hypocenter locations (Fig. 2) and the other is the centroid of the three locations. The weights assigned to the JMA, USGS, and Harvard hypocenter locations are 0.2 each, while the weight assigned to the centroid is 0.4 . Further to account for possible variability of the hypocenter location, deviation from the sampled location is modeled as a uniform random radius between 0 and $20 \mathrm{~km}$ with isotropic directionality.

Finally, to ensure that the synthesized slip distributions are realistic with respect to the seismological knowledge of earthquake rupture in the region, two additional constraints are implemented to determine the final acceptance of the generated source models. The first constraint requires that the ratio of the asperity area $S_{\mathrm{a}}$ to the total rupture area $S$ of the candidate slip distribution falls between 0.15 and 0.25 , where $S_{\mathrm{a}}$ is defined as the total area of sub-faults that have slip values greater than $1.5 D_{\text {ave }}$. This criterion is based on the empirical finding by Murotani et al. (2013) that for large subduction earthquakes, typically $S_{\mathrm{a}} / S$ is about 0.20 . The second constraint requires that the simulated earthquake slip is more concentrated in the shallow part of the fault plane rather than the deep part (Fig. 2), which is in agreement with the inverted source models for the 2011 Tohoku earthquake (Goda et al., 2014). Specifically, a candidate slip distribution is accepted if the total slip in the shallow segments (shaded sub-faults in Fig. 2) has a slip concentration between 60 and $75 \%$ in terms of total slip across the fault plane. Multiple slip distributions are simulated until a sufficient number of acceptable source models are generated. In this study, 100 source models that meet all the criteria mentioned previously are generated for each of six moment magnitudes ranging from $M_{\mathrm{w}} 8.0$ to $M_{\mathrm{w}} 9.0$ with 0.2 units step (i.e., in total, 600 source models are generated). Note that the sample size of 100 is selected based on the authors' previous experience in tsunami sensitivity analysis (Goda et al., 2014) and practical restrictions of computational resources.

Figure 4 shows synthesized earthquake source models for six moment magnitudes. Note that the source models shown in the figure are from the 100 accepted source models only. In the figure, mean and maximum slip values of the source models are indicated. Inspection of the illustrated six source models for different earthquake magnitudes indicates that both fault plane size and slip values increase significantly with moment magnitude. The location, size, and extent of the asperity areas also change significantly. Although not shown in Fig. 4, features of the 100 source models for the same moment magnitude also vary significantly. In particular, the locations of the asperity areas move around within the fault plane; this variability can be regarded as due to the inherent uncertainty of earthquake rupture process in the context of tsunami early warning where only macroscopic earthquake information is available. In the case study, the effects due to errors in earthquake magnitudes and the effects of within-scenario variability of earthquake rupture on estimated tsunami loss will be quantified and compared.

\subsection{Tsunami inundation modeling}

Tsunami modeling is carried out using a well-tested numerical code (Goto et al., 1997) that is capable of generating off-shore tsunami propagation and run-up/inundation by evaluating nonlinear shallow water equations using a leap-frog staggered-grid finite difference scheme. The runup/inundation calculation is performed by a moving boundary approach, where a dry or wet condition of a computational cell is determined based on total water depth in comparison with its elevation. The computational domains are nested at five resolutions (i.e., 1350, 450, 150, 50, and $10 \mathrm{~m}$ domains). In this study, due to the computational reasons, the smallest grid size of the nested data is set to $50 \mathrm{~m}$.

A complete data set of bathymetry/elevation, coastal/riverside structures (e.g., breakwater and levees), and surface roughness is obtained from the Miyagi prefectural government. The ocean-floor topography data are based on the 1:50,000 bathymetric charts and JTOPO30 database developed by Japan Hydrographic Association and based on the nautical charts developed by Japan Coastal Guard. The raw data are gridded using triangulated irregular network. The land elevation data are based on the $5 \mathrm{~m}$ grid digital elevation model (DEM) developed by the Geospatial Information Authority of Japan. The raw data are obtained from airborne laser surveys and aerial photographic surveys. These data have measurement errors of less than $1.0 \mathrm{~m}$ horizontally and of 0.3 to $0.7 \mathrm{~m}$ vertically (as standard deviation). The tidal fluctuation is not taken into account in this study.

The elevation data of the coastal/riverside structures are provided by municipalities in Miyagi Prefecture. In the coastal/riverside structural data set, structures having dimensions less than $10 \mathrm{~m}$ only are represented, noting that those having dimensions greater than $10 \mathrm{~m}$ are included in the DEM data. In the tsunami simulation, the coastal/riverside structures are represented by a vertical wall at one or two sides of the computational cells. To evaluate the volume of water that overpasses these walls, Homma's overflowing formulae are employed. 
(a)

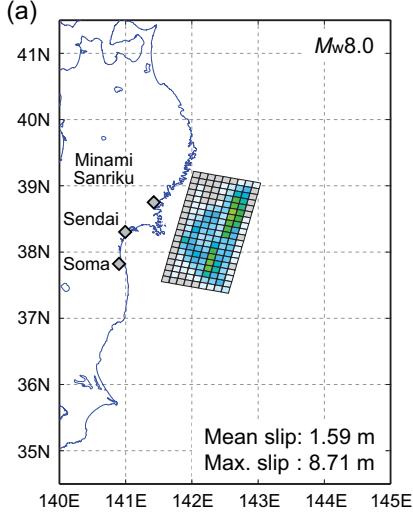

(d)

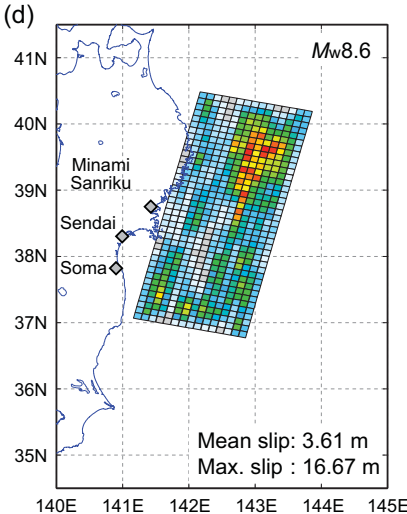

(b)

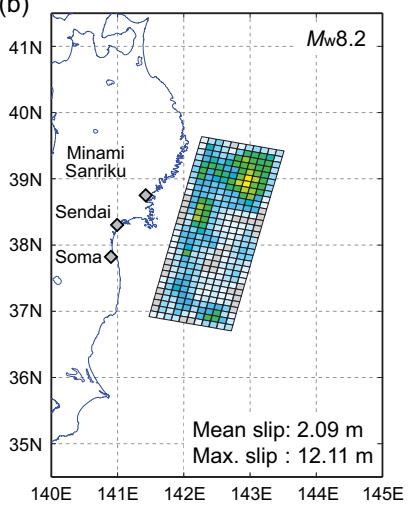

(e)

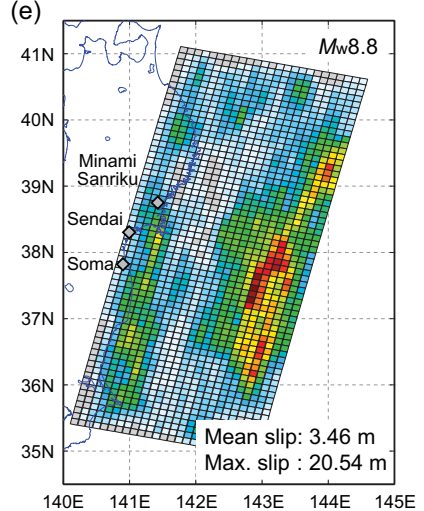

(c)
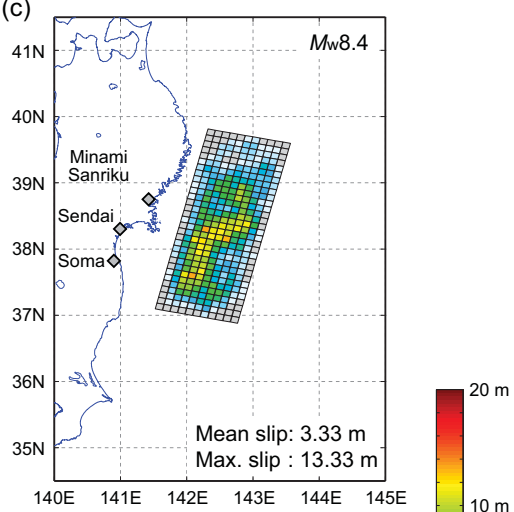

(f)

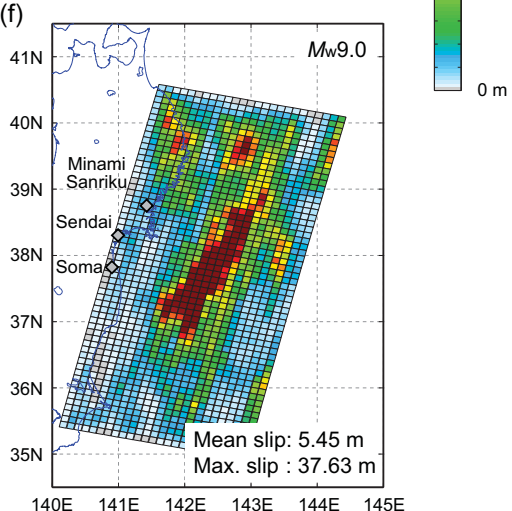

Figure 4. Synthesized earthquake source models: (a) $M_{\mathrm{W}} 8.0$, (b) $M_{\mathrm{W}} 8.2$, (c) $M_{\mathrm{W}} 8.4$, (d) $M_{\mathrm{W}} 8.6$, (e) $M_{\mathrm{W}} 8.8$, and (f) $M_{\mathrm{w}} 9.0$.

The bottom friction is evaluated using Manning's formula following the Japan Society of Civil Engineers standard (2002). The Manning coefficients are assigned to computational cells based on national land use data in Japan: $0.02 \mathrm{~m}^{-1 / 3} \mathrm{~s}$ for agricultural land, $0.025 \mathrm{~m}^{-1 / 3} \mathrm{~s}$ for ocean/water, $0.03 \mathrm{~m}^{-1 / 3} \mathrm{~s}$ for forest vegetation, $0.04 \mathrm{~m}^{-1 / 3} \mathrm{~s}$ for low-density residential areas, $0.06 \mathrm{~m}^{-1 / 3} \mathrm{~s}$ for moderatedensity residential areas, and $0.08 \mathrm{~m}^{-1 / 3} \mathrm{~s}$ for high-density residential areas.

Differences in earthquake slip result in different boundary conditions for tsunami propagation and run-up. In tsunami simulation, the initial water surface elevation is evaluated based on formulae by Okada (1985) and Tanioka and Satake (1996). The latter equation accounts for the effects of horizontal seafloor movements in the case of steep seafloor, inducing additional vertical water dislocation. The fault rupture is assumed to occur instantaneously, and numerical tsunami calculation is performed for duration of $2 \mathrm{~h}$ with an integration time step of $0.5 \mathrm{~s}$. For each case, the maximum inundation depths at all in-land computational cells ( $50 \mathrm{~m}$ grids) are obtained by subtracting the DEM data from the calculated maximum wave heights.

\subsection{Exposure data and cost information}

An extensive tsunami damage database for the 2011 Tohoku earthquake is available from the Ministry of Land, Infrastructure, and Transportation (MLIT) of the Japanese Government (MLIT, 2014). In the database, each building located in the affected areas is classified according to different attributes, such as geographical location, structural material, story number, tsunami inundation depth, and sustained damage level. The material types are categorized into: reinforced concrete (RC), steel, wood, masonry, and unknown, whereas the number of stories is divided into: 1-story, 2-story, and 3+-story. In this study, all buildings that are located between Soma City (south) to Minamisanriku City (north) and have information on material and story number are considered for assessing the tsunami damage and loss. There are 86219 buildings in total, consisting of 1446 RC structures, 4866 steel structures, 72506 wood structures, and 7401 masonry structures. The spatial distribution of the building portfolio is shown in Fig. 5a. Note that the map shown in Fig. 5a is based on the Japanese plane orthogonal coordinate system (which uses GRS80 as Earth ellipsoid and Gauss-Krüger map projection). The buildings are concentrated in the Sendai coastal plain. 

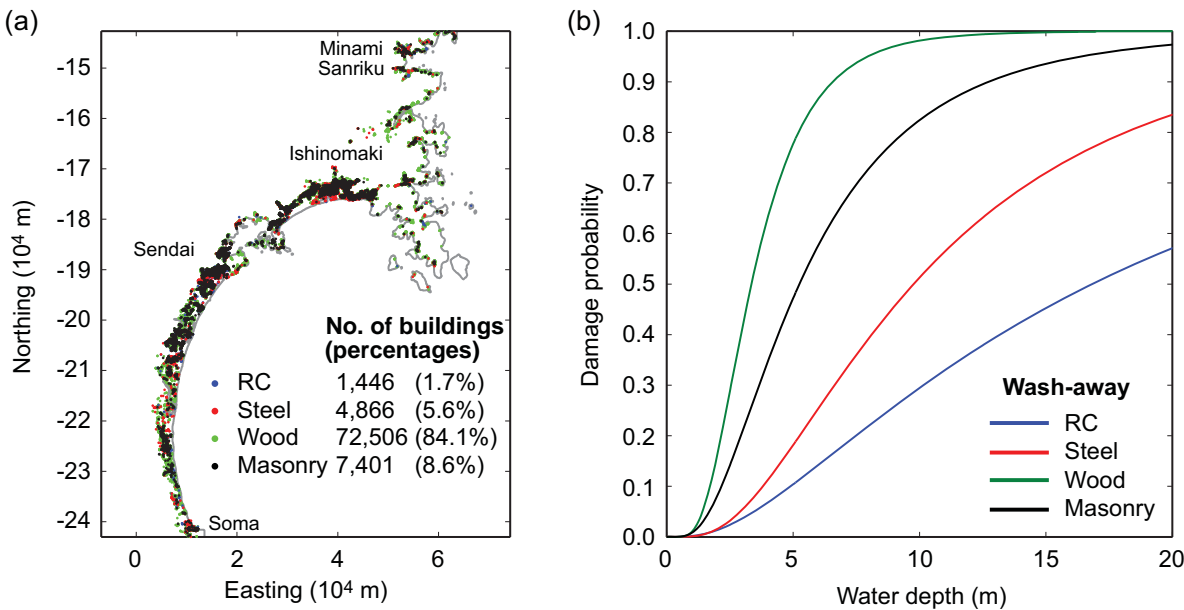

Figure 5. (a) Spatial distribution of buildings in Miyagi Prefecture, and (b) tsunami fragility curves for wash-away damage state. The map in (a) is shown in the Japanese plane orthogonal coordinate system.

For tsunami loss estimation, cost information for repairs and reconstruction is needed. Because the MLIT database does not contain occupancy information for individual buildings, simplified cost models for replacement that are based on building cost statistics (i.e., unit costs and footprint areas) are adopted by classifying buildings into residential houses (wood) and commercial stores/offices ( $\mathrm{RC} /$ steel/masonry). It is considered that the unit costs for houses and stores/offices can be approximated by the lognormal distribution; the mean and coefficient of variation $(\mathrm{CoV})$ are obtained from the regional building data statistics maintained by the MLIT. More specifically, the following cost information is adopted (USD $1=$ JPY 100; note that this conversion rate is an average over recent years and is adopted for simplicity): mean unit cost $=1600 \mathrm{USD} \mathrm{m}^{-2}$, $\mathrm{CoV}=0.320$, and floor area $=130 \mathrm{~m}^{2}$ for wooden houses; and mean unit cost $=1500 \mathrm{USD} \mathrm{m}^{-2}, \mathrm{CoV}=0.318$, and floor area $=540 \mathrm{~m}^{2}$ for stores/offices.

\subsection{Tsunami damage assessment and loss estimation}

Structural vulnerability against tsunami loading can be modeled by empirical tsunami fragility curves, which relate tsunami intensity measures (IM) to tsunami damage states (DS) statistically. The MLIT database defines seven discrete levels to describe the severity of tsunami damage: no damage, minor damage, moderate damage, major damage, complete damage, collapse, and wash-away. Using the MLIT tsunami damage database for the 2011 Tohoku tsunami, Suppasri et al. (2013) developed regional tsunami fragility models by distinguishing tsunami damage data according to the structural materials and the number of stories. The refinement for the different material types as well as for the number of stories is desirable, because the tsunami capacities for RC, steel, wood, and masonry buildings differ significantly (Koshimura et al., 2009; Suppasri et al., 2013; Tarbotton et al., 2015). Figure $5 b$ shows four fragility curves that correspond to the wash-away damage state for four material types, indicating that wood structures are more vulnerable in comparison with others.

The exceedance probability of damage state $\mathrm{ds}_{i}$ for a given value im is expressed as

$P\left(\mathrm{DS} \geq \mathrm{ds}_{i} \mid \mathrm{im}\right)=\Phi\left(\left[\ln (\mathrm{im})-\mu_{\ln \mathrm{IM} \mid \mathrm{DS}}\right] / \sigma_{\ln \operatorname{IM} \mid \mathrm{DS}}\right)$,

where $\Phi$ is the cumulative distribution function of the standard normal variate, and $\mu_{\ln \mathrm{IM} \mid \mathrm{DS}_{i}}$ and $\sigma_{\ln \mathrm{IM} \mid \mathrm{DS}_{i}}$ are the mean and standard deviation of $\operatorname{lnIM} \mid \mathrm{DS}_{i}$, respectively. For mutually exclusive damage states that are defined in a discrete manner, the probability of being in $\mathrm{ds}_{i}$ is given by

$p\left(\mathrm{ds}_{i} \mid \mathrm{im}\right)=P\left(\mathrm{DS} \geq \mathrm{ds}_{i} \mid \mathrm{im}\right)-P\left(\mathrm{DS} \geq \mathrm{ds}_{i+1} \mid \mathrm{im}\right)$.

Note that $\mathrm{ds}_{i+1}$ is severer than $\mathrm{ds}_{i}$ (i.e., $\left.P\left(\mathrm{DS} \geq \mathrm{ds}_{i+1} \mid \mathrm{im}\right)<P\left(\mathrm{DS} \geq \mathrm{ds}_{i} \mid \mathrm{im}\right)\right)$. For each building, probabilities of attaining particular damage states $p(\mathrm{ds} \mid \mathrm{im})$ can be estimated. By taking into account variability of source models (for a given scenario magnitude), the cumulative distribution functions of aggregate tsunami risk metrics, such as the number of buildings falling into a specific damage state, can be evaluated through Monte Carlo sampling of damage states for the buildings of interest (Goda and Song, 2016).

Finally, by incorporating the cost models for different buildings (Sect. 2.4), the tsunami damage information can be transformed into tsunami loss information for individual buildings as well as building portfolios. The loss ratios in terms of replacement cost of a damaged building for the seven damage levels (i.e., from no damage to wash-away) can be assigned as: 0.0, 0.05, 0.2, 0.4, 0.6, 1.0, and 1.0 (MLIT, 2014). Using the damage state probability $p(\mathrm{ds})$ and loss ratio $R_{\mathrm{L}}(\mathrm{ds})$, tsunami damage cost for a given tsunami hazard 
(a)

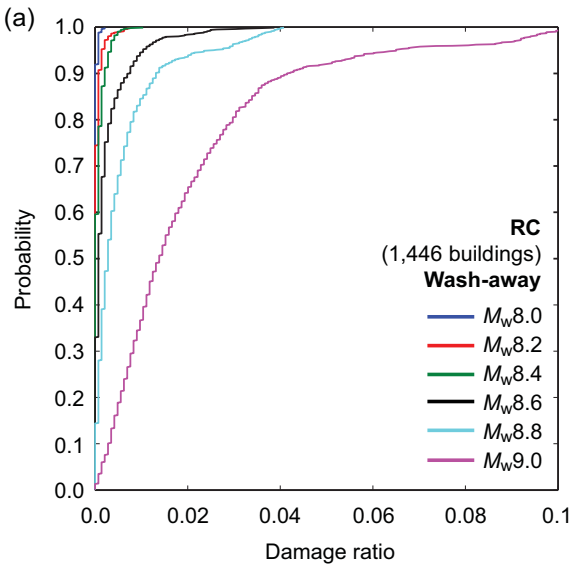

(c)

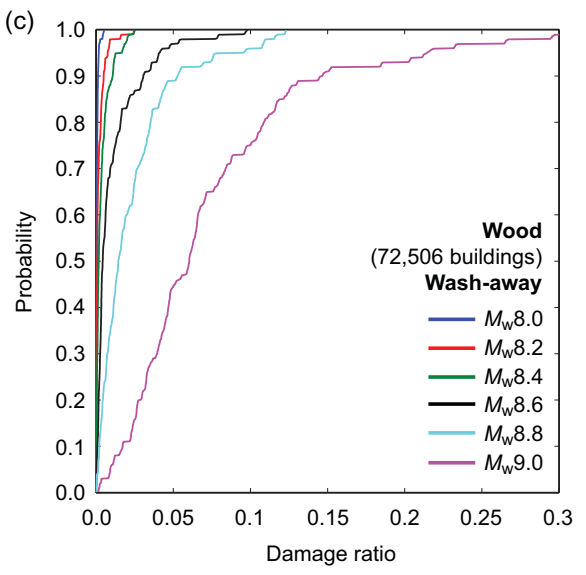

(b)

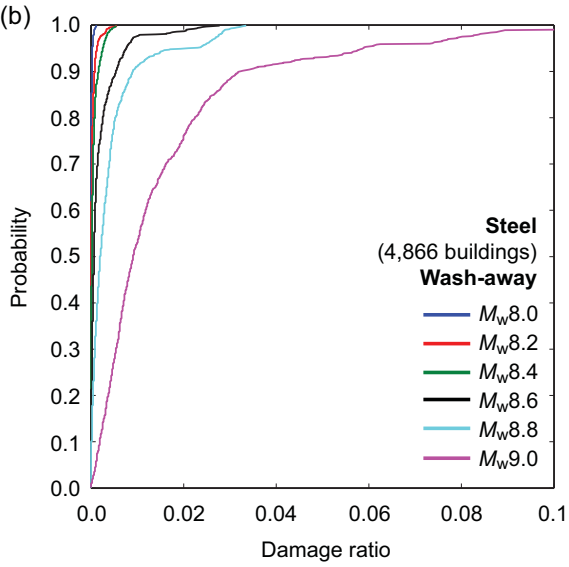

(d)

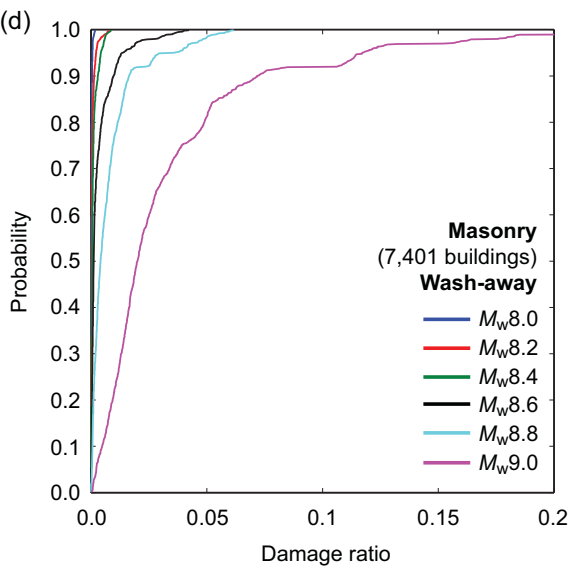

Figure 6. Probability distributions of wash-away damage ratios (i.e., percentages of damaged buildings to all buildings) for different earthquake scenarios by distinguishing material types: (a) RC, (b) steel, (c) wood, and (d) masonry.

intensity can be calculated as (for discrete cases)

$L=C_{\mathrm{R}} \sum_{i=1}^{7} p\left(\mathrm{ds}_{i}\right) \times R_{\mathrm{L}}\left(\mathrm{ds}_{i}\right)$,

where $C_{\mathrm{R}}$ is the replacement cost of a building. The tsunami loss curve can be used for deciding upon various tsunami risk mitigation actions. In the context of tsunami warning, differences of the loss curves for different scenario magnitudes are the quantitative estimates of the errors due to inaccurate source information. Moreover, the tsunami loss curve can be used to define critical scenarios for tsunami hazard mapping purposes. These are investigated quantitatively in Sect. 3.

\section{Application to major tsunami events in the Tohoku region of Japan}

Focusing on the building portfolio in Miyagi Prefecture, the effects of underestimation/errors of earthquake magnitude are investigated in the context of tsunami early warning and tsunami risk assessment. The investigations are conducted using the probabilistic tsunami loss estimation tool developed in Sect. 2. In total, six scenario magnitudes from $M_{\mathrm{W}} 8.0$ to $M_{\mathrm{W}} 9.0$ are considered, and for each magnitude 100 stochastic source models are generated to represent the within-scenario uncertainty of the earthquake rupture. In Sect. 3.1, two questions are mainly considered: When the magnitude is in error, what would be the impact in terms of tsunami loss prediction? And, what is the uncertainty of predicted tsunami loss given a moment magnitude and hypocenter location? The former question is relevant when the warnings need to be given shortly after a very large seismic event, whereas the latter is always present in issuing tsunami early warnings. Comparison of the two cases will provide emergency officers with valuable insights related to their challenging tasks in an extreme situation. In Sect. 3.2, the usefulness of rigorous tsunami risk assessment is discussed in defining critical hazard scenarios based on potential consequences due to tsunami disasters.

\subsection{Tsunami loss curves for different earthquake scenarios}

The developed loss estimation tools can produce various results of tsunami risk assessment. Figure 6, for instance, dis- 

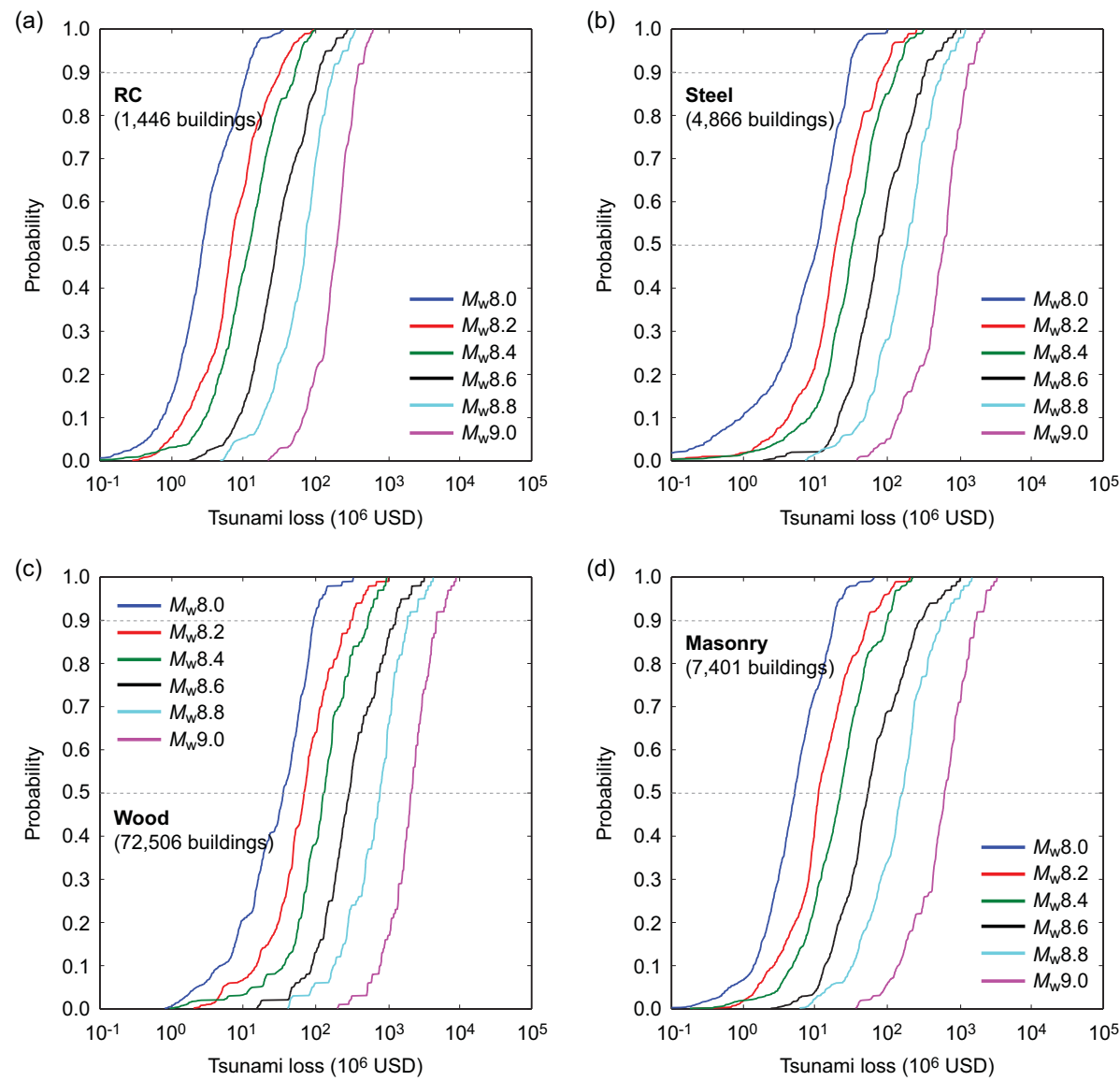

Figure 7. Probability distributions of tsunami loss for different earthquake scenarios by distinguishing material types: (a) RC, (b) steel, (c) wood, and (d) masonry.

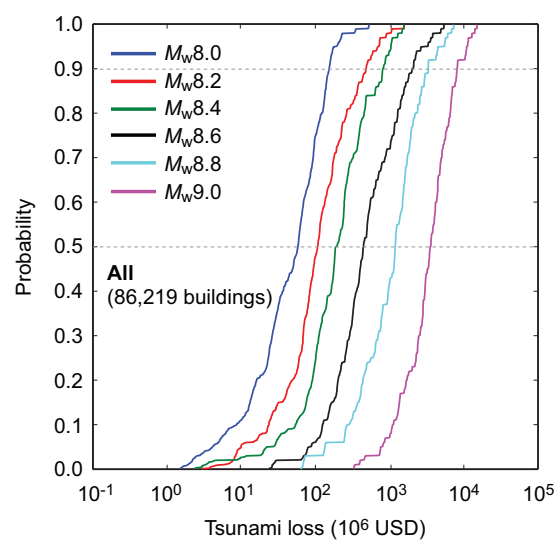

Figure 8. Probability distributions of total tsunami loss for different earthquake scenarios.

plays probability distributions of the number of buildings that are in the wash-away damage state for different scenario magnitudes by distinguishing building material types. The results are shown in terms of damage ratio (i.e., percentage of damaged buildings with respect to all buildings for each material type). The results clearly indicate that for all material types the occurrence of wash-away damage in the considered building portfolio becomes increasingly more frequent. It is noteworthy that although appearances of these damage ratio curves for different material types are similar (i.e., how relative positions of these curves change with the increase in $M_{\mathrm{w}}$ ), the horizontal axes of Fig. 6 (i.e., damage ratio values) are different for the four material types. The maximum range of the damage ratio for wood structures is greater than those for other structures, reflecting the higher vulnerability of these structures (Fig. 5b; note that spatial distribution of the buildings also has influence). The observations regarding the changes of the damage ratio curves with respect to earthquake magnitude (as in Fig. 6) are applicable to different damage states.

To evaluate the economic consequences due to tsunami events with different scenario magnitudes, probability distributions of tsunami loss for the building portfolio are obtained for different magnitude values and for different material types. The results are shown in Fig. 7. One notable difference of the results shown in Figs. 6 and 7 (apart from the incorporation of damage cost models) is that the tsunami loss 

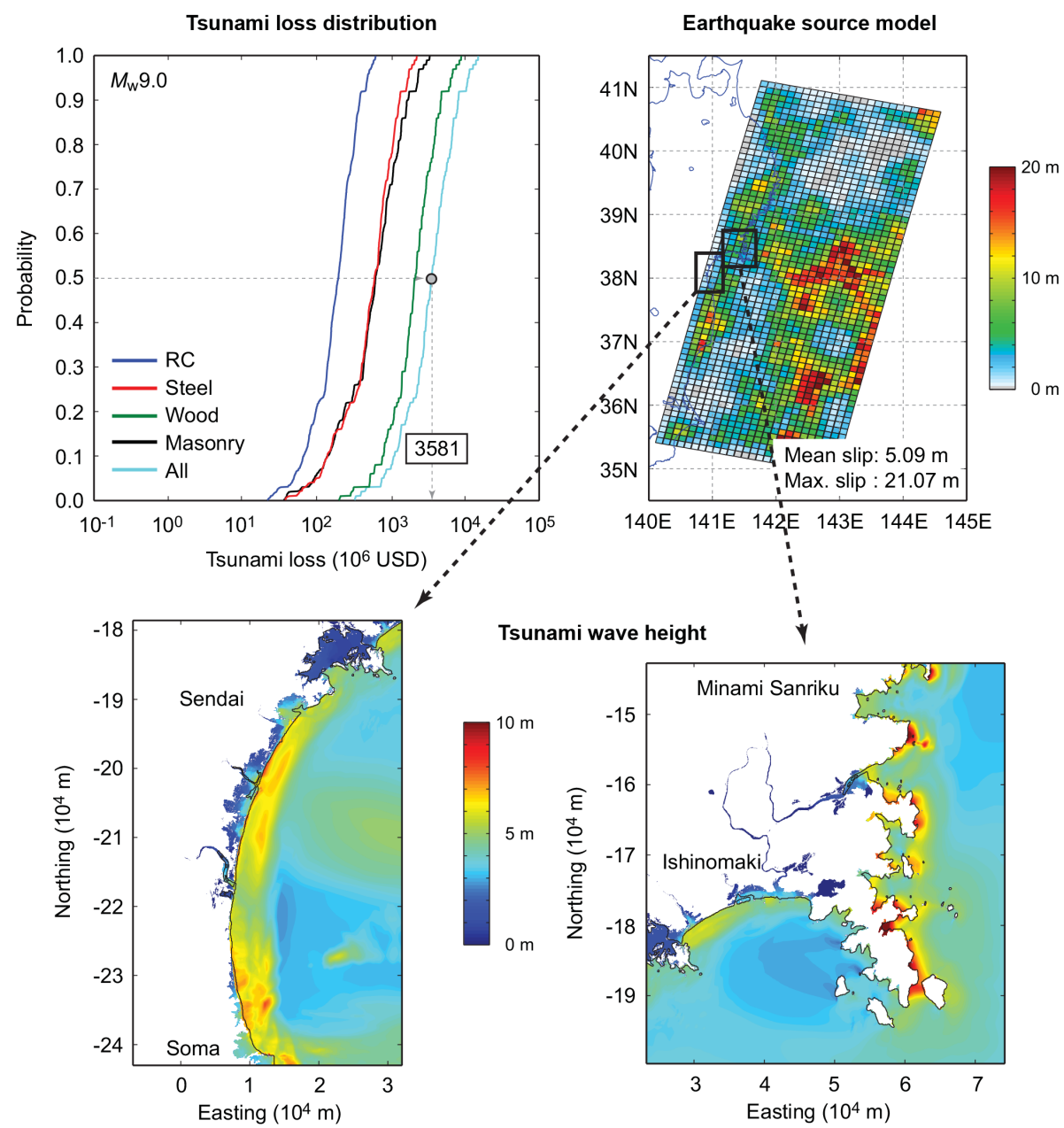

Figure 9. Earthquake source model and inundation height maps that correspond to a critical tsunami loss scenario. For the inundation height maps (bottom two figures), results are shown in the Japanese plane orthogonal coordinate system.

curve includes all buildings with different damage states by weighting their relative impact based on the tsunami damage cost, whereas only a subset of buildings that sustain a specific damage state is considered in developing the damage ratio curve. Hence, the tsunami loss curve is more useful for assessing overall tsunami impact for the building portfolio. Inspection of Fig. 7 suggests that for all material types, the tsunami loss curves become more severe with increasing magnitude, noting that the horizontal axes of Fig. 7 are logarithmic with base 10. This indicates that the tsunami loss generation is an exponential process with respect to earthquake magnitude.

To discuss the effects of underestimation/errors of earthquake magnitude on total tsunami loss, tsunami loss curves for the entire building portfolio are shown in Fig. 8 by considering different earthquake scenario magnitudes. It is obvious that the tsunami loss curve shifts towards the right with the increase in $M_{\mathrm{w}}$, and its increment per magnitude change is approximately constant or slightly increasing (to conclude this definitively, more simulations are necessary).
For example, at the median probability level, the tsunami loss increases by about a factor of 100 from $M_{\mathrm{w}} 8.0$ to $M_{\mathrm{w}} 9.0$ scenarios. Practically, this means that the over-/underestimation of earthquake magnitude by certain units in the tsunami warning might correspond to very different situations in terms of potential consequences. If there is a possibility that the estimated earthquake information, which is obtained quickly, is in error or biased, the risk manager may wish to issue tsunami warnings by taking into account the uncertainty associated with risk predictions.

On the other hand, the within-scenario variability of the tsunami loss curve is caused by the uncertainty associated with detailed earthquake slip characteristics that are not captured by the macroscopic earthquake information. The results shown in Fig. 8 indicate that this variability is significant, and the main contributor of the variability is the spatial slip distribution, especially the location and extent of major asperities with respect to the building portfolio. For instance, the range between the minimum and maximum loss scenarios can be as large as a factor of 100 for the $M_{\mathrm{w}} 8.0$ case, 

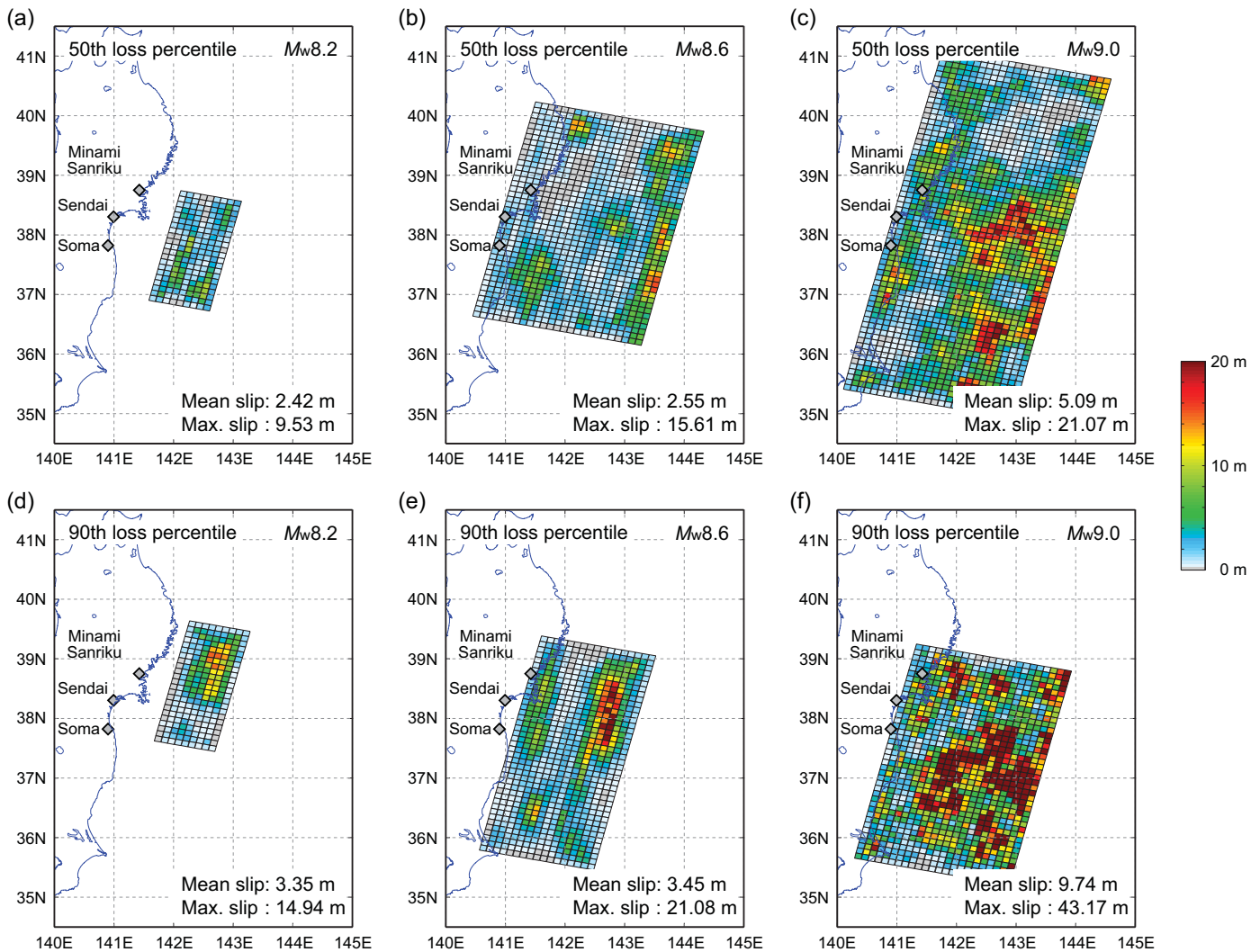

Figure 10. Earthquake source models corresponding to critical loss scenarios: (a) 50th loss percentile for $M_{\mathrm{W}} 8.2$, (b) 50th loss percentile for $M_{\mathrm{W}} 8.6$, (c) 50th loss percentile for $M_{\mathrm{W}} 9.0$, (d) 90 th loss percentile for $M_{\mathrm{W}} 8.2$, (e) 90 th loss percentile for $M_{\mathrm{W}} 8.6$, (f) 90 th loss percentile for $M_{\mathrm{W}} 9.0$.

and it tends to decrease gradually as the scenario magnitude increases. Because the position of the fault rupture plane has more influence on tsunami loss when the earthquake size is small, the within-scenario variability of tsunami loss is greater for smaller earthquake magnitudes. The withinscenario variability of tsunami loss is grossly comparable with the tsunami loss differences caused by the biases in earthquake magnitude (depending on the probability levels of that are referred to in the tsunami loss curves). This highlights the importance of the earthquake rupture process and slip distribution for accurate tsunami risk prediction. The results suggest that the further deployment of deep oceanbottom sensors near the source areas (e.g., Iinuma et al., 2012) will not only improve the early detection of tsunami waves but also help constrain the earthquake rupture process more rapidly.

\subsection{Critical tsunami loss scenarios and corresponding source and inundation maps}

An integrated understanding of the quantitative tsunami loss results is useful for defining critical scenarios for tsunami hazard mapping and risk management purposes, and thus enhances the resilience of coastal communities against catas- trophic tsunami disasters. This section aims at demonstrating the advantages that can be gained from such rigorous risk assessments.

Figure 9 illustrates a procedure to develop inundation hazard maps that are based on a critical tsunami loss scenario. The top-left panel of Fig. 9 shows the tsunami loss curves for the $M_{\mathrm{w}} 9.0$ scenario (same as those shown in Figs. 7 and 8). Each point of the loss curve corresponds to a specific source model and inundation results- for example, the median case in terms of tsunami loss distribution for the entire building portfolio is focused on (which is indicated by a circle). The tsunami loss is estimated as USD 3581 million. The earthquake source model that causes the median tsunami loss is shown in the top-right panel of Fig. 9. The source model has large concentrations of earthquake slips in the shallow segments of the fault plane. Furthermore, two maximum tsunami wave height contours for Soma to Sendai and for Ishinomaki to Minamisanriku that correspond to the source model shown in the top-right panel are presented in the bottom-left and bottom-right panels, respectively. It can be observed from the inundation maps that the tsunami loss is generated in the coastal plain areas (south of Sendai), low-lying parts of Ishinomaki, and locations along the ria coast in northern Miyagi Prefecture. The source models and inundation maps that are 

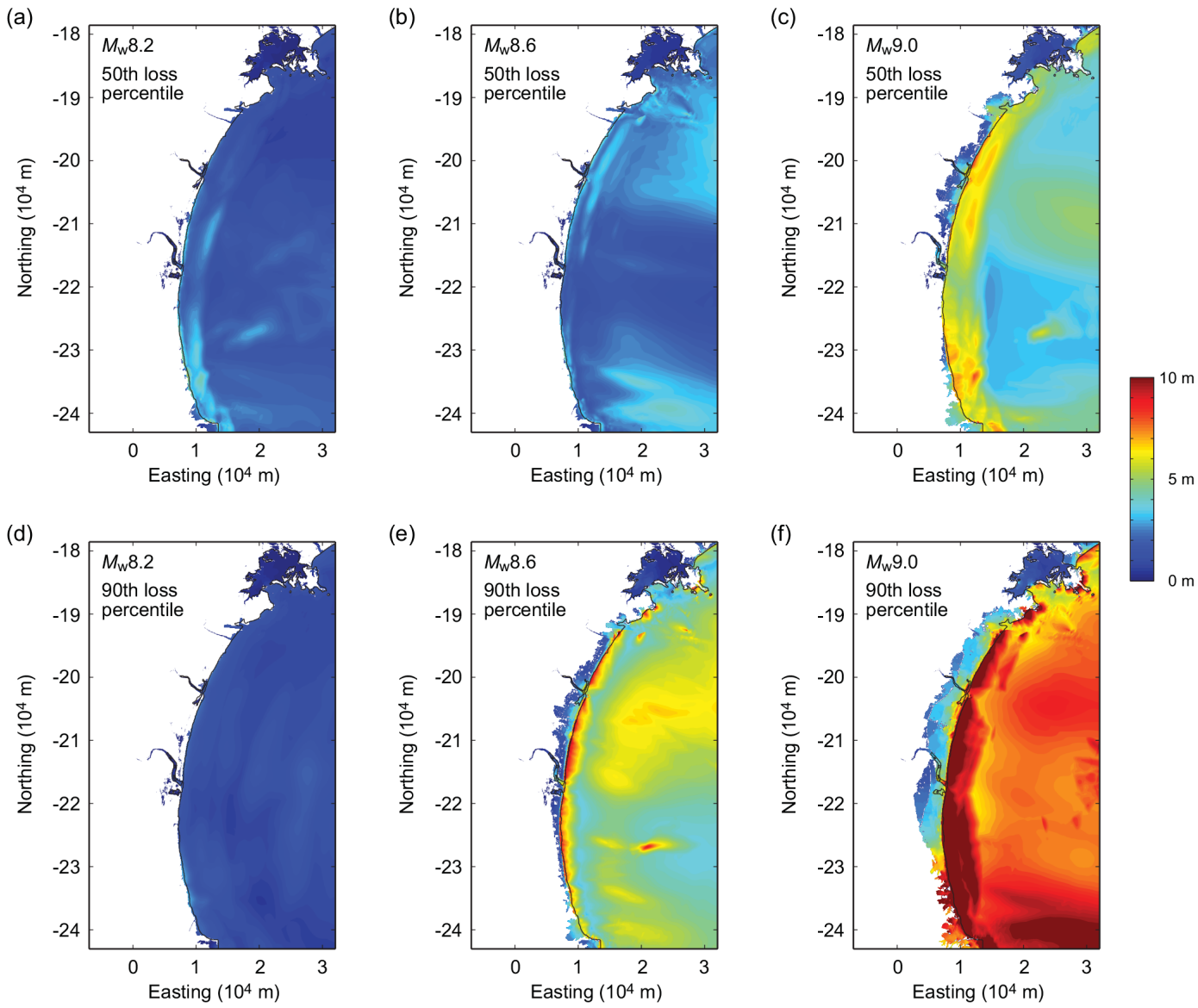

Figure 11. Inundation height maps in Sendai-Soma areas corresponding to critical loss scenarios: (a) 50th loss percentile for $M_{\mathrm{W}} 8.2$, (b) 50 th loss percentile for $M_{\mathrm{W}} 8.6$, (c) 50 th loss percentile for $M_{\mathrm{W}} 9.0$, (d) 90 th loss percentile for $M_{\mathrm{W}} 8.2$, (e) 90 th loss percentile for $M_{\mathrm{W}} 8.6$, (f) 90 th loss percentile for $M_{\mathrm{W}} 9.0$. The inundation height maps are shown in the Japanese plane orthogonal coordinate system.

identified through the loss calculations are useful because the scenario and hazard information is directly associated with the tsunami loss percentile (i.e., median loss for the $M_{\mathrm{w}} 9.0$ scenario). It is noted that the hazard maps based on critical tsunami loss are different from conventional tsunami hazard maps that are prepared for coastal cities and towns. The conventional tsunami hazard maps lack the link with the potential consequences and, importantly, the assessment of the uncertainty. The proposed tsunami hazard mapping method, although it requires much significant calculation, is more transparent and meaningful for communicating the tsunami risk with stakeholders. Therefore, it can be used as decisionsupport systems for tsunami risk reduction.

To further demonstrate how the proposed tsunami hazard mapping method can be used for various situations, earthquake source models and inundation height maps in Soma-Sendai and Ishinomaki-Minamisanriku areas are developed by considering three scenario magnitudes (i.e., $M_{\mathrm{w}} 8.2, M_{\mathrm{w}} 8.6$, and $\left.M_{\mathrm{w}} 9.0\right)$ and two loss percentiles (i.e., 50th and 90th percentiles); the loss curves that are referred to are shown in Fig. 8. The results are shown in Figs. 10-
12. The source models for different scenarios and loss percentiles (Fig. 10) clearly show that both rupture area and slip statistics increase significantly with the scenario magnitude and with the loss percentile. Furthermore, it can be observed that with the increase in the loss percentile, the location of the asperities tends to be positioned directly across the areas where the building portfolio is distributed (i.e., between Soma and Minamisanriku); thus larger tsunami waves are radiated towards the buildings of interest. The effects of greater tsunami waves can be appreciated by inspecting the tsunami inundation maps for the two local areas. In the Soma-Sendai areas (Fig. 11), the maximum tsunami wave heights near the coastal line and in the inundated areas increase rapidly with more severe tsunami scenarios. In the Ishinomaki-Minamisanriku areas (Fig. 12), two features can be seen in different topographical regions. In the ria coast, the maximum tsunami wave heights become larger but the spatial extent of the inundation does not change significantly when more severe tsunami scenarios are considered. On the other hand, in the coastal plain of Ishinomaki, both maximum tsunami wave heights and inundated areas increase 

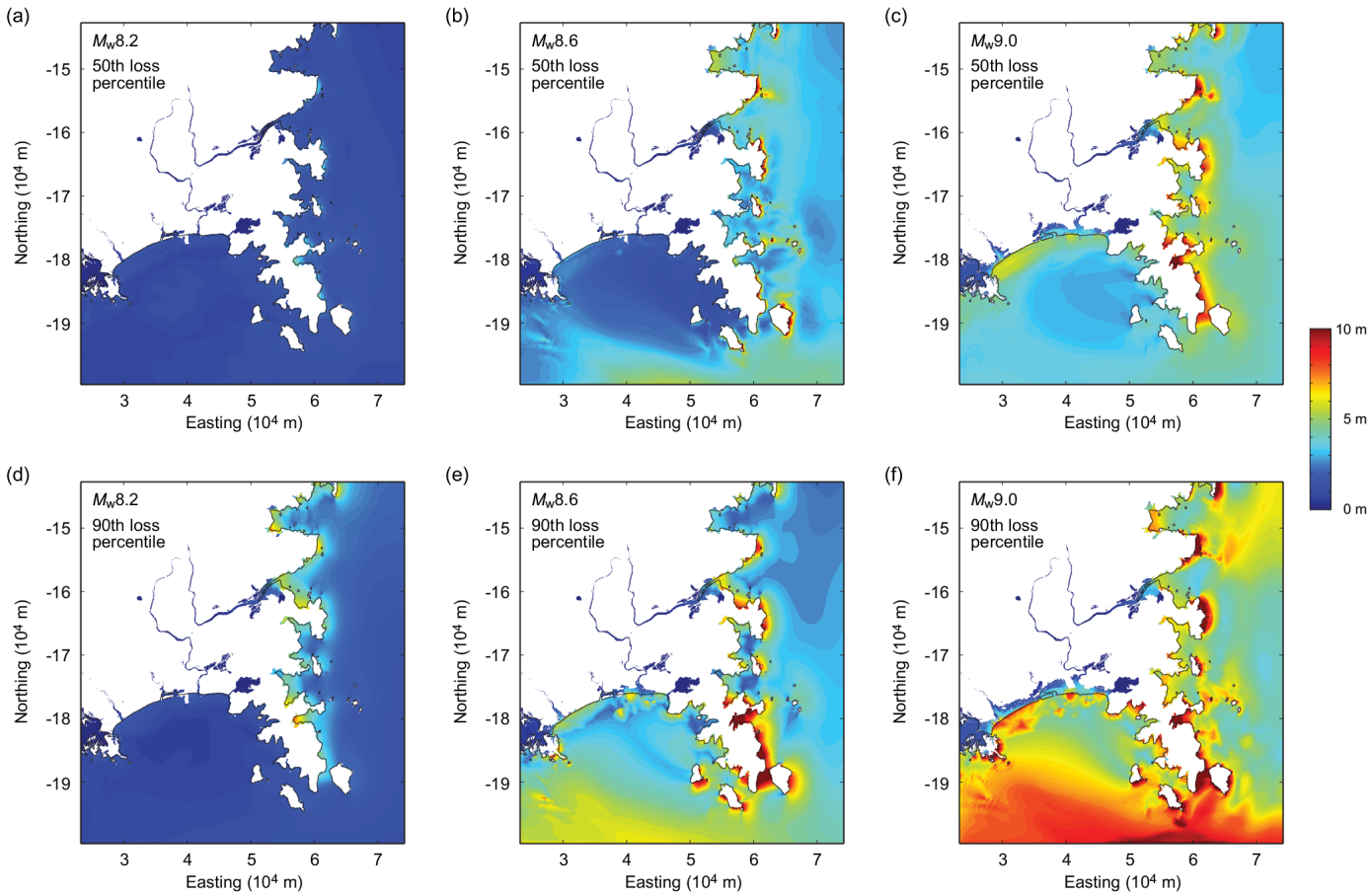

Figure 12. Inundation height maps in Ishinomaki-Minamisanriku areas corresponding to critical loss scenarios: (a) 50th loss percentile for $M_{\mathrm{W}} 8.2$, (b) 50th loss percentile for $M_{\mathrm{W}} 8.6$, (c) 50th loss percentile for $M_{\mathrm{W}} 9.0$, (d) 90 th loss percentile for $M_{\mathrm{W}} 8.0$, (e) 90 th loss percentile for $M_{\mathrm{W}} 8.6$, (f) 90 th loss percentile for $M_{\mathrm{w}}$ 9.0. The inundation height maps are shown in the Japanese plane orthogonal coordinate system.

with more severe tsunami scenarios, similar to the cases for the Soma-Sendai areas.

\section{Conclusions}

Issuing accurate and prompt tsunami warnings is vital for reducing the potential consequences due to catastrophic tsunami disasters. Recognizing the unavoidable uncertainty in the estimation of earthquake information that is used for tsunami early warnings as well as the uncertainty of the earthquake rupture process (e.g., slip distribution), it is important to evaluate the effects of such uncertainties on the tsunami risk predictions quantitatively. For this purpose, a case study focusing on tsunamigenic events in the Tohoku region of Japan was set up to illustrate the significance of the problems. The new comprehensive probabilistic tsunami loss model was developed by implementing various scaling relationships for the key source parameters and stochastic spectral methods of synthesizing the spatial earthquake slip distribution. The generated stochastic source models for different scenario magnitudes were used as input in Monte Carlo tsunami inundation simulation and subsequent tsunami damage assessments. The developed tsunami risk assessment tool can produce tsunami loss curves for a range of scenario magnitudes. Focusing on the building portfolio in Miyagi Prefecture, the effects of underestimation/errors of earthquake magnitude were investigated in the context of tsunami early warning and tsunami risk assessment, and were compared with the within-scenario variability of the tsunami loss due to the uncertain earthquake rupture process. In addition, a procedure to define critical hazard scenarios based on potential consequences of tsunami disasters was suggested to promote more transparency and effectiveness in communicating tsunami risks.

The main conclusions of this study are as follows.

The tsunami loss generation process is exponential with respect to earthquake magnitude. Therefore, biases/errors in earthquake source information (magnitude and hypocenter location) can have major influence on the potential consequences of the tsunami event in the context of tsunami early warning and risk prediction.

At the median probability level, for instance, total tsunami loss increases by about a factor of 100 from $M_{\mathrm{w}} 8.0$ to $M_{\mathrm{w}} 9.0$ scenarios (note that various loss quantities can be extracted from the calculated loss curves). Such quantitative information of predicted tsunami risk is useful for risk managers who decide to issue warnings and evacuation orders.

For a given scenario magnitude, tsunami loss curves vary significantly due to uncertain earthquake rupture characteristics that are not captured by the macroscopic earthquake information. The within-scenario variability of tsunami loss is comparable with the tsunami loss differences caused by the biases in earthquake magnitude. 
The definition of critical tsunami scenarios based on probabilistic tsunami loss calculations are useful for more effective tsunami hazard mapping and risk management. The deficiency of current tsunami hazard maps can be addressed by explicitly taking into account uncertainty associated with hazard scenarios and their characteristics.

Acknowledgements. The bathymetry and elevation data for the Tohoku region were provided by the Miyagi prefectural government. The tsunami damage data for the 2011 Tohoku earthquake were obtained from the Ministry of Land, Infrastructure, and Transportation (http://www.mlit.go.jp/toshi/toshi-hukkou-arkaibu.html). This work was supported by the Natural Environment Research Council through the Consortium on Risk in the Environment: Diagnostics, Integration, Benchmarking, Learning and Elicitation (CREDIBLE; $\mathrm{NE} / \mathrm{J} 017450 / 1)$. The authors are grateful to Tomohiro Yasuda, Nobuhito Mori, James Daniell (referee), and Jan Dettmer (referee) for their useful discussions and suggestions.

Edited by: T. Wagener

Reviewed by: J. E. Daniell and one anonymous referee

\section{References}

Cyranoski, D.: Japan's tsunami warning system retreats, Nature, doi:10.1038/news.2011.477, 2011.

Fraser, S., Pomonis, A., Raby, A., Goda, K., Chian, S. C., Macabuag, J., Offord, M., Saito, K., and Sammonds, P.: Tsunami damage to coastal defences and buildings in the March 11th 2011 $M_{\mathrm{W}} 9.0$ Great East Japan earthquake and tsunami, Bull. Earthq. Eng., 11, 205-239, 2013.

Fukutani, Y., Suppasri, A., and Imamura, F.: Stochastic analysis and uncertainty assessment of tsunami wave height using a random source parameter model that targets a Tohoku-type earthquake fault, Stoch. Environ. Res. Risk Assess., 29, 1763-1779, 2015.

Geist, E. L. and Parsons, T.: Probabilistic analysis of tsunami hazards, Nat. Hazards, 37, 277-314, 2006.

Goda, K. and Song, J.: Uncertainty modeling and visualization for tsunami hazard and risk mapping: a case study for the 2011 Tohoku earthquake, Stoch. Environ. Res. Risk Assess., doi:10.1007/s00477-015-1146-x, 2016.

Goda, K., Mai, P. M., Yasuda, T., and Mori, N.: Sensitivity of tsunami wave profiles and inundation simulations to earthquake slip and fault geometry for the 2011 Tohoku earthquake, Earth Plan. Space, 66, 1-20, doi:10.1186/1880-5981-66-105, 2014.

Goda, K., Yasuda, T., Mori, N., and Mai, P. M. () Variability of tsunami inundation footprints considering stochastic scenarios based on a single rupture model: application to the 2011 Tohoku earthquake, J. Geophys. Res.-Oceans 120, 4552-4575, 2015.

Goto, C., Ogawa, Y., Shuto, N., and Imamura, F.: Numerical method of tsunami simulation with the leap-frog scheme, IOC Manual, UNESCO, No. 35, Paris, France, 1997.

Horspool, N., Pranantyo, I., Griffin, J., Latief, H., Natawidjaja, D. H., Kongko, W., Cipta, A., Bustaman, B., Anugrah, S. D., and Thio, H. K.: A probabilistic tsunami hazard assessment for Indonesia, Nat. Hazards Earth Syst. Sci., 14, 3105-3122, doi:10.5194/nhess-14-3105-2014, 2014.
Hoshiba, M. and Ozaki, T.: Earthquake early warning and tsunami warning of the Japan Meteorological Agency, and their performance in the 2011 off the Pacific Coast of Tohoku earthquake $\left(M_{\mathrm{W}} 9.0\right)$, in: Early Warning for Geological Disasters, edited by: Wenzel, F. and Zschau, J., 1-28, 2014.

Iinuma, T., Hino, R., Kido, M., Inazu, D., Osada, Y., Ito, Y., Ohzono, M., Tsushima, H., Suzuki, S., Fujimoto, H., and Miura, S.: Coseismic slip distribution of the 2011 off the Pacific Coast of Tohoku Earthquake (M9.0) refined by means of seafloor geodetic data, J. Geophys. Res., 117, B07409, doi:10.1029/2012JB009186, 2012.

Japan Society of Civil Engineers: Tsunami assessment method for nuclear power plants in Japan, available at: https://www.jsce.or. jp/committee/ceofnp/Tsunami/eng/JSCE_Tsunami_060519.pdf (last access: 1 October 2015), 2002.

Kagan, Y. and Jackson, D. D.: Tohoku earthquake: a surprise?, Bull. Seismol. Soc. Am., 103, 1181-1194, 2013.

Kanamori, H. and Rivera, L.: Source inversion of W phase: speeding up seismic tsunami warning, Geophys. J. Int., 175, 222-238, 2008.

Koshimura, S., Oie, T., Yanagisawa, H., and Imamura, F.: Developing fragility functions for tsunami damage estimation using numerical model and post-tsunami data from Banda Aceh, Indonesia, Coast. Eng. J., 51, 243-273, 2009.

Mai, P. M. and Beroza, G. C.: A spatial random field model to characterize complexity in earthquake slip, J. Geophys. Res. Solid Earth, 107, 2308, doi:10.1029/2001JB000588, 2002.

Mai, P. M., Spudich, P., and Boatwright, J.: Hypocenter locations in finite-source rupture models, Bull. Seismol. Soc. Am., 95, 965980, 2005.

Melgar, D., Crowell, B. W., Geng, J., Allen, R. M., Bock, Y., Riquelme, S., Hill, E. M., Protti, M., and Ganas, A.: Earthquake magnitude calculation without saturation from the scaling of peak ground displacement, Geophys. Res. Lett., 42, 51975205, 2015.

Ministry of Land Infrastructure and Transportation (MILT): Survey of tsunami damage condition, available at: http://www.mlit.go. jp/toshi/toshi-hukkou-arkaibu.html, last access: 1 July 2014.

Mueller, C., Power, W. L., Fraser, S., and Wang, X.: Effects of rupture complexity on local tsunami inundation: implications for probabilistic tsunami hazard assessment by example, J. Geophys. Res. Solid Earth, 120, 488-502, doi:10.1002/2014JB011301, 2015.

Murata, S., Imamura, F., Katoh, K., Kawata, Y., Takahashi, S., and Takayama, T.: Tsunami: to survive from tsunami, World Scientific Publishing, New Jersey, 302 pp., 2010.

Murotani, S., Satake, K., and Fujii, Y.: Scaling relations of seismic moment, rupture area, average slip, and asperity size for $M \sim 9$ subduction-zone earthquakes, Geophys Res Lett 40:5070-5074, 2013.

Okada, Y.: Surface deformation due to shear and tensile faults in a half-space, Bull. Seismol. Soc. Am., 75, 1135-1154, 1985.

Pardo-Iguzquiza, E. and Chica-Olmo, M.: The Fourier integral method: an efficient spectral method for simulation of random fields, Math. Geol., 25, 177-217, 1993.

Satake, K., Fujii, Y., Harada, T., and Namegaya, Y.: Time and space distribution of coseismic slip of the 2011 Tohoku earthquake as inferred from tsunami waveform data, Bull. Seismol. Soc. Am. 103, 1473-1492, 2013. 
Suppasri, A., Mas, E., Charvet, I., Gunasekera, R., Imai, K., Fukutani, Y., Abe, Y., and Imamura, F.: Building damage characteristics based on surveyed data and fragility curves of the 2011 Great East Japan tsunami, Nat. Hazards, 66, 319-341, 2013.

Tanioka, Y. and Satake, K: Tsunami generation by horizontal displacement of ocean bottom, Geophys. Res. Lett., 23, 861-864, 1996.

Tarbotton, C., Dall'Osso, F., Dominey-Howes, D., and Goff, J.: The use of empirical vulnerability functions to assess the response of buildings to tsunami impact: comparative review and summary of best practice, Earth Sci. Rev., 142, 120-134, 2015.
Thingbaijam, K. K. S. and Mai, P. M.: Evidence for truncated exponential probability distribution of earthquake slip, tentatively accepted for Bull. Seismol. Soc. Am., 2016.

Wells, D. L. and Coppersmith, K. J.: New empirical relationships among magnitude, rupture length, rupture width, rupture area, and surface displacement, Bull. Seismol. Soc. Am., 84, 974$1002,1994$.

Wiebe, D. M. and Cox, D. T.: Application of fragility curves to estimate building damage and economic loss at a community scale: a case study of Seaside, Oregon, Nat. Hazards, 71, 2043-2061, 2014. 